\title{
What has psychoanalysis got to do with Happiness? Reclaiming the positive in psychoanalytic psychotherapy
}

Keywords: positive, happiness, resilience, reclamation, psychoanalysis

\begin{abstract}
This paper questions whether what is a strength of psychoanalysis, its focus on painful and difficult experiences and its ability to remain in touch with the negative aspects of the personality, might also be an Achilles heel. The paper discusses research from neuroscience, developmental and social psychology to argue that more attention needs to be given to how we work with more positive and hopeful aspects of the personality, and that otherwise psychoanalytic psychotherapists are not working with the whole person. Some clinical examples are used to illustrate how these ideas might be used.
\end{abstract}

Graham Music is a Consultant Child and Adolescent Psychotherapist working in the NHS and an adult psychotherapist in private practice. He is Associate Clinical Director of the Child and Family Department at the Tavistock Clinic, London, where his activities include clinical work in fostering and adoption, training and management. He teaches and supervises regularly on a range of courses at the Tavistock and elsewhere, including in Sicily and Istanbul. Address for correspondence:- Tavistock Centre, 120 Belsize Park, London NW3 5BA gmusic@ tavi-port.nhs.uk

\section{Introduction}

This paper looks at an area of psychic life that psychoanalysis has under-theorised, that of feeling good, and resilience. In the last few years there has been something of a new bandwagon, to do with thinking about 'happiness' and the importance of positive emotions, which has caught the media's and public's imagination. Richard Layard's book called 'Happiness' (Layard 2005) is just one of a whole swathe of texts in popular psychology sections of bookshops discussing the subject, and there is also a large and increasingly influential school of positive psychology, based on the thinking of Martin Seligman (Seligman 2002). Such ideas present a challenge to psychoanalytic thinking that requires that we do more than simply dismiss this agenda as superficial, or defensive or 'syrupy'. Much psychoanalytic thinking, particularly in the Kleinian tradition, has placed particular emphasis on the negative, on the ability to process painful affects, on working with more destructive parts of the personality, and on the developmental significance of developing 'depressive' capacities. I do not for one moment want to suggest that we throw the baby out with the bathwater, or abandon any of these central therapeutic preoccupations. I do think though that we also need other strings to our bow so that we can help patients grow psychologically in other ways, and at the same time still know that we are doing psychoanalysis. At an early stage in one of my psychotherapy trainings I was given a very clear message that the job of the psychoanalytic psychotherapist was to help patients manage and process the negative, and the explicit communication to me was that the job of therapy was to 'look after the negative and the positive will look after itself'. Over the years I have found that clinically this is not enough, and that some patients' lives have simply not improved enough by only 'looking after the negative'.

Sometimes colleagues, as well as supervisees in training, report somewhat shamefacedly the work they have done which has galvanised more hopeful and positive aspects of the personality, and they commonly report doubts about whether their work is 'really' psychoanalytic. I hope to argue that it is. Whilst we have been good at helping people reach a state of 'ordinary unhappiness', as Freud seemingly suggested we do, we have been less good at facilitating more positive states of mind. Although I do not subscribe to their philosophies, I think that we have more to learn from often derided optimistic literary figures such as Dr. Pangloss 
(Voltaire 1947) and Pollyanna (Porter 1913) than we care to admit. Pangloss is of course the much maligned, and annoyingly optimistic character in Voltaire's Candide, for whom everything is 'the best in the best of all possible worlds'. Pollyanna is the even more ridiculed, overly optimistic orphan who finds something hopeful in every situation. To mention two other famous fictional characters, this time from Winnie the Pooh (Milne \& Shepard 1958), many of us might feel more at ease with traits displayed by patients like the doleful and gloomily pessimistic Eeyore and are less sure what to do with more Tigger-ish presentations, and in this paper I suggest that both kinds of traits are important.

The bread-and-butter of my work with patients has always been in ensuring that they have a space which provides containment for suffering and despair. Sometimes though, such understanding or emotional relief is not enough. With one 46 year old female patient who had been very depressed and anxious, several years were spent working through despair so that, from being fearful of such negative affects, she could almost consider them to be rather like old friends about whom she had mixed feeling, but with whom she could now get along. Although this seemed like real progress, she still felt unconfident, fearful, and unable to enjoy whole areas of her life. To take one maybe small and hardly momentous area of functioning, she was fearful of swimming and of water in general, and indeed we spent a lot of time thinking about the reasons why she was so fearful. We discussed the fact that she was forcibly made to jump into swimming pools at her rather cruel-sounding first school, when she had felt like she was drowning. She also felt fairly certain that she remembered some real experiences of being ill-treated in a bath by a nanny when very young. There was room to ponder and associate to what 'immersion' meant for her. She reflected thoughtfully about how trust, letting herself go and 'immersing' herself in life, related to her relationship with her actual mother, and her internal maternal object, as well as her relationship with me.

This all felt productive, and along with other therapeutic work, she began to feel far more at ease and less plagued by anxiety. The catch, though, was that she still could or would not dare to act positively in much of her life, a typical example being her continued fear of getting into water. On hot days on holiday whilst her family and friends were frolicking in the sea or diving into a swimming pool, she remained in the dry, with a nagging sense of failure and this was symbolic of several areas of her life where she felt inhibited and stymied, and to use her words, 'psychologically frozen'. The fact was that if such a feeling was to change then at some point she would need to 'take the plunge', and I had to question myself as to whether it was my job to help her do this or not. In the event I did, but often by using convoluted pseudo-interpretations to mask what were really encouragements. I said things like 'it is hard for you to believe that I think you really could do this', or 'maybe you are clinging to an idea that you are still 5 years old and that the water will feel as frightening.' Thankfully the patient knew what I was really saying and even at one point asked wryly 'are you actually encouraging me?' She did soon dare to learn to swim, and in this and other areas began to feel more confident, taking risks at work and in her relationships too, and she seemed to develop more of a sense of her own capacities and agency. The dangers of such an approach are many. I could be seen as seductive, or as encouraging pseudo-capacities masking anxieties, and most importantly, would I be able to still pick up and work with negative transference phenomena? However I hope to argue that if we do not help patients feel better about themselves as well as managing unhappiness then we are only doing half the job of therapy.

One of the most famous early examples of a psychoanalyst working in this way was a patient whom Balint (Balint 1968) described in the Basic Fault. She was someone who apparently had lots of potential but seemed to always let herself down. She was bright but failed her exams. She seemed to be lively and sociable but did not manage a relationship. She was someone who had learnt to keep her feet firmly planted on the ground and said to Balint that, despite wishing to, she had never managed to do a somersault. His famous, noninterpretative response was 'what about it now?' at which point the patient proceeded to get up and somersault across the consulting room. Balint writes of this as a turning point, a 'new beginning', after which 'many changes followed in her emotional, social, and professional life, all towards greater freedom and 
elasticity.' Balint, I think, characterised this moment as a form of regression, whereas one might prefer to think of this as his encouragement of something more 'progressive' and developmental, of risk-taking and daring to throw caution to the winds, of being able to act without always calculating the consequences. Balint also described what happened rather passively, saying that the somersault 'emerged', whereas in fact it is hard not to see this as a form of active facilitation by the therapist. The question I pose in this paper is whether there is a place for such interventions in our work as psychoanalytic psychotherapists.

\section{Some Psychological Evidence}

Research in the last few decades has shown that being happy is not at all the same as not being unhappy, and similarly the absence of happiness is quite different from the presence of unhappiness. The ways in which our minds and brains process negative emotions are different from those whereby we process positive emotions, using different brain circuitry and hormonal systems for instance. We might assume that the greater number of happy experiences one has, the less unhappy one is or vice-versa, but research shows that this is not the case (Bradburn \& Noll 1969). People who are the most social and outgoing also tend to experience more positive feelings, but these same people do not necessarily experience less negative emotions than shy, more depressed people.

Predicting and anticipating danger is a much needed capacity which presumably has aided human survival. It is linked to our fear response, and being aware of the possibility that bad things are about to happen. Of course it is also possible to do too much of this, as we might see in morbidly depressed people who always expect the worst. Research has shown that in marriages where there are equal numbers of positive and negative exchanges, both partners tend to be unhappy, and indeed according to this research a marriage requires 5 or 6 times more positive than negative interactions for it to be considered satisfying (Gottman 1994). Our taste buds detect sweetness if we place just one part of sugar into 200 parts of a sample of food, but we are far better at spotting bitterness, which we perceive if there is only 1 part per 2,000,000 (Ito et al. 1998). If we think of this as partly a metaphor, it is also the case that some people are more likely to spot the bitter tastes in life than others, and some taste sweetness that others do not perceive.

The psychological and biological systems for seeing the cup as half full or empty, for having positive and negative emotions, have turned out to be very different. For example, we know that the presence of dopamine is linked with more positive emotion. The dopamine system is central to goal-directed behaviour, such as seeking and reaching out. Dopamine levels are low in depressed people, and for example depressed mothers have low dopamine levels, and indeed, as early as a month old, so do their infants.

Experiments looking at the parts of the brain that are activated when we feel positive or negative have found that people experiencing more negative emotions generally have high activation in the right frontal cortex, and people who show more optimistic and positive emotion have a higher left frontal brain activation (Demaree et al. 2005). If people have damage to the left sides of their brains they are more likely to be depressed, and if the damage is to the right side they are more likely to show mania. Either one of these separate systems might be dominant in a particular moment. The negative emotion system is often called the defensive system and is concerned with factors such as avoiding danger. Its activation leads to more pessimism, more worry, and its motivation will primarily be to seek safety and security. It is this, I suspect, that most psychoanalytic psychotherapists are primarily working with. The positive affect system is sometimes called the appetitive system and leads to interest, pleasure, hope, is linked with moving towards and not away (e.g. in extroversion), and aims to increase good feelings, rather than just avoid negative ones. These two tasks involve very different hormonal and neuronal activity and therapeutic work with each might entail a different approach. Some people rely more on their appetitive system and others on a more defensive one, depending on whether they veer more towards caution, fight-flight and inhibition as opposed to aiming 
to more actively fulfil their interests and desires. This echoes Jung's (Jung 1921) important concepts of 'introversion and extroversion'. It seems that people need to build two different sets of capacities, to manage both negative and positive affects and experiences. Children and adults who are traumatized and have had little positive experience might well need help to cope with and process the enormous pain and upset they have experienced, otherwise it might remain to haunt them. However they also need help to enjoy the good things in life, to build up hope and the ability to reach out for things. Yet the two systems can work separately, and as Zautra (Zautra 2003) has pointed out, people can be high on one or the other, or high on both, or low on both. People who show high levels of behavioural inhibition, that is those with a dominant defensive system, do not necessarily report more or less positive affect than other people.

\section{Why it matters}

The distinction between positive and negative affect is by no means purely an academic one but has consequences for vital aspects of our lives, not least our life expectancy and health. For example, the more right brain activity and negative emotion we experience, the weaker our immune systems are likely to be, something that has been shown in experiments by exposing people to the flu virus, and noting that those with more activity in their right pre-frontal cortex were far more likely to succumb to the virus and had less antiflu antibodies (Davidson et al. 2003). Davidson is one of the main researchers in this area, and he also collaborated with the Dalai Lama and trained people in mindfulness meditation.. He found that this increased the activity in their left pre-frontal cortex, and also heightened their immune systems. Davidson has shown the same brain asymmetry to be true of children and this is linked to their personality traits. Toddlers were observed in play sessions and classified into 2 groups. Some were relatively inhibited and others uninhibited, this being measured by looking at factors such as how exploratory the children were, how near to their attachment figures they stayed, or how talkative or outgoing they seemed. Over time the inhibited children, whilst at rest, had greater right-side activation and the more outgoing ones had greater left side activity.

Stress has a bad effect on the immune system whilst happiness seems to enhance it. A fascinating retrospective study was done of nuns in Milwaukee (Danner et al. 2001). They all wrote diaries when they entered their Order in the 1930's, and these were recently examined in detail by a team of researchers, for example in terms of how many positive and negative words were used. Although their lives once in the convent barely differed in terms of routine, or diet or general ways of spending their days, their relative longevity certainly did differ, and in direct proportion to how happy they were six decades earlier. One nun for example wrote 'The past year has been a very happy one. Now I look forward with eager joy to receiving the Holy Habit of Our Lady...'. Such words as 'happy', 'eager', 'look forward' and 'joy' were absent from the more negative diaries. Of the less positive nuns, for example, two thirds had died before reaching 85 years old, whereas $90 \%$ of the happy ones were still going strong. It was the amount of positive rather than negative feelings that predicted longevity. The nun quoted above was still alive at 98 years old, and on average the happier ones lived about 9 years longer than the more pessimistic ones. These nuns presumably would have had more left pre-frontal cortex activity and a boosted immune system. This was a complex study, in the end looking at nearly 300 nuns in 3 different convents, scoring on several scales and checked for inter-rater reliability, and it found that for every $1 \%$ increase in positive emotion there followed a $1.4 \%$ decrease in mortality rates.

Researchers (cf Zautra 2003 p81) have similarly found that in people experiencing the same psychological stressor, those who are less badly affected had found a way to believe that some good had come out of their experiences, and had taken some hope or positive learning from them, just as Pollyanna might have encouraged! These 2 groups showed no differences in their levels of psychological distress; they all showed similar levels of anxiety, depression and similar states of unrest. However it was their levels of positive feeling that differentiated them. In a meta-study looking at 18 studies, it was found that those who coped better and were more resilient had a more positive outlook generally, and they had also created some meaning out of their situations and had found something interesting and hopeful in their predicament, even if 
they had no less distress than those who fared worse. This research is not suggesting that distress should be avoided or denied, but that something hopeful can come out of it.

Positive emotions seem to be a protective factor in many ways. Helgeson and Fritz (Helgeson \& Fritz 1999) studied about 300 heart patients and isolated as many factors as they could to try to work out what might predict better recovery or less likelihood of further heart attacks. The factors that most predicted recovery turned out to be self-esteem and optimism, and those scoring high on these attributes were over 3 times more likely to survive. It is not that the presence of negative emotions predicted relapse but the presence of positive ones prevented it. Similar research has shown that the more positive affect one feels the less the likelihood of contracting various illnesses (e.g. Cohen et al. 2006), irrespective of the extent of negative emotions. For example, more positive feelings were associated with higher levels of healthy Natural Killer cell activity (Valdimarsdottir \& Bovbjerg 1997), with those showing some psychological distress gaining the biggest immune system boost from positive affect states. Resilience is partly the ability to find strength and something positive in the face of adversity, which is not the same as not having any distress or denying it. Studies show that it is not that a global, overall positive attitude will necessarily boost immunity under stressful conditions, but that a positive response to stressful situations makes a big difference.

Stress and negative emotions can be damaging in themselves and so there is a kind of 'double whammy' in that positive affect raises immunity, but stress and anxiety lowers it. In one of many pieces of similar research university students were given slight wounds by their experimenters, and strikingly, those given wounds in the holidays healed much faster and better than those inflicted in the middle of exams, a much more stressful time. In fact the stressed students took an average of $40 \%$ longer to heal (Glaser et al. 1999). Similarly, couples with more marital hostility heal less well after severe medical procedures (Kiecolt-Glaser et al. 2005). Stress can lower the immune system, leading to less effective healing mechanisms.

We need good experiences to thrive. Place rats in bleak and deprived environments; and on most measures they do badly. Those that have had no maternal care tend to be over-reactive and easily startled (ie with a heightened defensive system), but they also show less interest in or appetite for pleasurable experiences, such as the taste of sugar (Graham et al. 1999). Similarly the lack of positive input exerts its price on human emotional development. Neglected children are more likely to show a lack of interest in life, and little positive emotion, as studies of more barren institutional care-regimes as long ago as the 1940's have shown (e.g. Spitz 1945). Anyone who saw pictures of the tragic examples of Romanian orphans at the end of the Ceausescu regime would be aware of the bleak worlds inhabited by these children, and research has also shown (O'Connor et al. 1999) that for many of them, particularly those who stayed longest, or who were treated worse, the bleakness continued long after institutionalisation and they struggled to appreciate what other children take for granted and enjoy.

By contrast good care is inoculatory. When experimenters (Francis et al. 1999) enriched the environments of rats by stroking and handling them, those mothers and pups who had been handled later licked and groomed their own pups, and this had a knock-on effect; the pups became more interested in suckling, and then ate more. As they grew older the licked and groomed pups had lower stress responses and higher immune systems. Maybe most strikingly, these pups became the mothers who in the next generation in turn licked and groomed their own infants. Good experiences seem to activate neural circuits of social engagement, stimulated by the hormone oxytocin, often dubbed the 'love hormone' linking with positive emotions; feelings of well-being and a heightened immune system.

As in other mammals the same processes can be seen in humans. Most children release oxytocin when cuddled by their parents or people who care for them, but a sample of the Romanian orphans mentioned above, who were adopted after deprived early years, were shown not to release oxytocin in the same way as children brought up in their birth families (Fries et al. 2005). Another study retrospectively looked at an American sample (Russek \& Schwartz 1997) of students who had been researched 35 years previously and 
were tracked down in middle-age. As part of the original study parents had been rated by the students as, for example caring or uncaring. Those students who had rated their parents as uncaring 35 years later had three and $a$ half times the rate of illness, these figures being derived via careful and complex medical tests. What was striking was that what seemed to give rise to better health was not the absence of uncaring parents, but rather it was the presence of at least one caring parent. Again good experiences inoculated against ill-health, and this is different from the effect of bad experiences.

\section{Optimism is natural in children: Research and a case example, Carol}

In psychoanalytic psychotherapy, the concept of defences against pain, or against omnipotence or omniscience, has played a central part in how clinical work has been approached. The person who seems over-confident, can be seen as manically omnipotent and defending against their littleness. Freud's Reality Principle suggested that the child who had a too grand sense of their knowledge or capacities should be helped to face the painful reality of their limitations. In recent years some psychoanalytic theorists working with children have challenged such ideas. In particular, Alvarez (Alvarez 1992) has suggested that with certain deprived children, if we interpret what we see as defences too quickly then we simply deflate patients. The child who jumps on the chair and shouts 'I am king of the castle' might be being defensive but for some children this can be the first experience of feeling strong and confident and they might revert to a more hopeless state if we interpret something like 'you want to be strong but really inside you feel little and hopeless'. In recent years there has been some research which suggests that it is helpful for a child to have a slightly overconfident view of themselves. Such confidence in fact aids actual competence later on as the psychologist Bjorklund (Bjorklund 2007) has shown. In an experiment children were asked to rate how well they understood the details of how mechanical devices such as a toaster or a music box worked, and kindergarten children gave themselves the highest ratings of all, their confident levels of self-belief barely lowered after they had heard an adult's 'proper' explanation of how these contraptions worked. Older children lowered their belief of their own understanding but not the little ones, and in fact a quarter even increased their ratings after hearing an adult's explanations (Mills \& Keil 2005). Generally we become more realistic as we get older but children when young tend to think they can climb higher mountains, balance more balls, score more goals and generally perform excellently, and they are adept at ignoring any evidence that contradicts such beliefs. For example, in the early years at school most children think they are one of the cleverest, a belief that only slowly subsides (Stipek \& Gralinski 1996).

Bjorklund describes such mental agility as a form of 'protective optimism' and not just a defensive process used to deny a painful reality. He explains such optimism developmentally in terms of its usefulness for children who have a lot to learn and need to both try out new things with some hope and confidence and also be able to persist at tasks that currently feel too difficult. He mentions another study of little children who were asked to predict how many pictures they would remember that they had been shown. Some massively overestimated how many they would remember and others were quite accurate. Maybe somewhat counterintuitively the children who overestimated the most on the first round, who we might have assumed had an almost delusional level of self belief, in fact tried out more strategies second time around and improved the most. Their optimism encouraged them to keep trying. Indeed many have argued something similar in relation to adults (e.g. Dunning et al. 2004), namely that a degree of over-optimism protects against depression and that depressed people often perceive things more accurately than more optimistic types. Indeed most adults are prone to such self-deceptive beliefs; we believe that we are better than average drivers (Horswill et al. 2004), and we generally tend to think of ourselves as more intelligent, better at our jobs and less prejudiced than our peers (Arkin et al. 1980), something that psychologists call 'self-serving attribution bias'. Of course within every age group we will see people ranging across a continuum between optimism and pessimism Pessimistic children, such as those who have been criticized a lot or who come from families with much depressed or negative thinking, are less likely to have the same degree of exaggerated optimism. Yet I do think that such attitudes and seemingly entrenched personality traits can shift to an extent, and that therapy can play a part in this, as I hope to show now. 


\section{Carol}

I undertook three times weekly psychotherapy with a 4 year old girl whom I call Carol. She was the third of 4 children, and the others were doing fine. She was born after a major house move and a loss of mother's father, and so her mother was in a considerably less robust state than she had been with the other children. She was a depressed little girl who had some autistic features, and could bear very little frustration, or change, and easily fell into extremely despairing states. She tended early on to flit from activity to activity, seemingly blown by whatever sensation overtook her in the moment. She gave up on things very easily. Trying to put two pieces of toy fencing together she soon said despairingly 'I can't' and then wailed 'I wanna see mummy'. She seemed to be plunged into depression by the slightest set-back. Tustin (Tustin 1992 p118) noted that 'such a child expects to do everything at the first attempt ... when he fails he desists from effort', and this picture fitted Carol only too well. She became fearful on hearing slight noises outside the room that I barely registered, and she quickly gave up on activities at the first hurdle in desultory fashion. When she saw me in the waiting room she always sat passively until I called her. I realised that I had to be extremely attuned to her emotional states or else she would retreat. Interpretations of any complexity simply went over her head, being experienced as unwelcome impingements.

The themes of damage and repair dominated many early sessions. She crashed a toy helicopter against a wall, and then took some sellotape and stuck it on the helicopter. I said 'you are mending it' and she said 'plaster'. She did the same thing next with a car and I, ever hopeful that she was identifying with a damaged part of herself that needs repair, said 'poor car is hurt and Carol is mending it'. Fortunately for Carol I had a supervisor who pointed out that I was on completely the wrong track. This was not depressive position reparation, but the sign of a fragile object (internal and external) that needed looking after. As the therapy proceeded I learnt to stress the strength of the crashes, not the damage and repair, and in time her crashes got louder and stronger as I echoed her newfound forcefulness with a strong voice of my own. I had been struck by her light ethereal quality and I often felt I could just blow her over, but slowly some inner strength began to form.

In one session I was surprised when out of her usual quietness she spontaneously began to sing 'the babies on the bus go wah wah wah' and when I joined in she stared at me long and hard and then came and sat next to me. This was unusual as her speech was generally muffled and indistinguishable, even more so when she was upset or disturbed. Often she barely lifted her head when asking me something and it was hard for me to know that her whispered sounds were directed at me or anyone. She seemed to have no sense of an object ready to receive her communications, little sense of agency or potency, and indeed even when most lively her play was rarely accompanied by words or babble. In the beginning I often spoke aloud about how sad she was, but this did not help. I was focussing on the wrong bits of her personality and just rubbing her nose in the sadness and despair with which she was all too familiar. She needed help to access some sense of anger and outrage. When in one session she threw a toy giraffe on the floor and I said clearly 'you really want to throw that silly giraffe away', she smiled and jumped on the table and proceeded to swing the giraffe around with almost a hint of triumph. I felt sure that this was developmentally hopeful.

In another session she picked up a telephone, a redundant one which I used in the therapy room, and she pulled it by its cord towards the edge of the table so that it teetered and was about to fall off. My heart was in my mouth as I foresaw that the phone would break apart, the pieces scattering everywhere, and she would collapse in a forlorn way, as so often. As it hit the floor, I gathered myself and managed to shout 'crash' loudly, trying to express the force, impact and shock, but also that these were all manageable. I could see she had been about to give up and cry, and that this could lead once again to her retreating to the corner for the rest of the session. I retrieved a few telephone parts and said 'we can fix it, look'. I replaced some, and she looked at me, as if not quite believing that disaster could be recovered from. When I had repaired the phone 
she wanted to start all over again, and this time she helped locate and replace the missing bits. One piece could not be found and again she was about to give up and I said 'Oh where is it, is it here? Or is it here?', pretending not to know where it was but showing faith that it could be found. Again her attention was retained, she did not give up, and in the forthcoming weeks this was re-enacted over and over. Soon it was her saying, as she looked for a piece, 'Oh I wonder where is it?', not simply copying me in an empty way but really identifying with an aspect of me. I worried whether my very active intervention equalled not staying with her painful experience of falling apart, but I became increasingly convinced that she needed someone to hold on to hope for her. I think that in much of our work I was allowing myself to be used as what Bollas (Bollas 1989) described as a 'transformational object', evoking as yet unrealised potentialities or 'idiomatic experiences' as she became bolder and "a centre of initiative' (Kohut 1977).

She still gave up on things too quickly, but also recovered more now. When she did not manage to cut through some string with her scissors, she listlessly put it down. Next time I intervened I said 'Carol is really trying, she is nearly there, it is cutting through', and when she eventually did cut a piece I would triumphantly say 'yes you did it'. She showed pleasure and excitement, and needed me to talk about these new feeling-states to help process and 'work through' the hopeful and positive feelings that most children take for granted. It was not long before Carol was managing such tasks alone, indeed becoming so much more buoyant and lively that her parents were beginning to worry that she was becoming 'naughty' and even 'anti-social!'

Following a missed bank holiday session she arrived at the clinic in a very forlorn mood, also having trodden in a puddle and soaked her socks. She almost refused to enter the room, and retreated under a blanket. She cried for a long time. Then she tried to get up and kick a ball but rather pathetically missed it and collapsed into a heap again. Comments such as 'how sad you are' made no difference. Her mood lasted for several sessions, and when I tried saying things like 'you are very cross with Mr. Music' that too made no inroad. I had to locate myself even more clearly as a bad object to rage at, and say loudly 'that silly stupid old Mr. Music, he went away, huh'. At this point she looked up, threw a plastic spoon right at me and we were back in business, as a whole pile of toys were flung in my direction and she then began playing again. Anger and outrage have the same 'outgoing' focus that one sees in more confident people, those whom Davidson showed to have higher left-brain activation and a sense of entitlement and agency. Presumably her pre-frontal left brain was suddenly firing on all cylinders.

There continued to be periods of therapy where pain and despair dominated, such as when she began primary school and cried again for weeks. She did need me to know and understand her despair as well. Yet she also needed to experience some resilience both inside and outside herself. A few months later, she inadvertently knocked a toy female figure behind a desk. I was expecting a despairing collapse but to my astonishment she instead called out 'you all right down there?' She then said 'I gonna get you out'. She then found some string, leant over the edge of the desk, dropped the string down, and called down 'I coming'. She then proceeded to tie the string to the toy, climbed back onto the desk, and got me to hold the other end of the string as she enacted heaving the string with strenuous effort. She play-acted wiping her brow, pulled again and I joined her in a triumphant 'one, two, three' and a loud 'YES' as she pulled the toy up. In the coming weeks this cycle was re-played with slight variations many times. I think the play sequence symbolised her identification with an internal figure who could pull her out of a black hole towards the light and was a sign of a more resilient internal object being established. Alvarez (Alvarez 1992) describes graphically the process of 'reclaiming' or bringing back a depressed patient towards life, just as a mother might need to do for a withdrawn baby. She argues that this is an essential aspect of psychoanalytic work with certain deprived patients. I think that much of the work with Carol was of that ilk.

Such children need help to develop a sense of optimism and of their own agency. Like Bjorklund's resilient 
children, Carol now did not give up so easily and could keep on trying. One might contrast such optimism with the children of depressed mothers that Murray (Murray 1992) or Field (Field et al. 2006) studied, who tend to be more passive, and with less sense of agency, or children who have been traumatised or neglected, whose sense of agency and confidence in themselves is so under-developed. Obviously there can be dangers in overestimating one's ability, but children like Carol run the opposite risk. They easily become hopeless, with little trust that they can make an impact on the world. Although reality must be faced, too much facing painful reality too early might not always be in a child's or adult's best interests

\section{Developing agency and control. Michael.}

Many experiments have shown that having some control over events reduces stress levels in subjects undergoing horrible experiences. Knowing what is going to happen, or feeling we have some control over it, makes a huge difference to how we feel. Babies who are responded to, with parents who are fairly consistent, and who feel they can influence their interactive partners, whether by crying, smiling or pointing, tend to be more confident and less stressed than babies whose parents are unpredictable and abusive, or neglectful and unresponsive. Many experiments have demonstrated the stress induced by what is now called 'learned helplessness' (Peterson et al. 1993). Give any animal a major stressor (the classic test was rather cruelly giving electric shocks to dogs), and then also give some of them some control over the event (in the case of the dogs this was a lever that could be flicked to stop the shocks), and those who have some control do not become as hopeless and helpless, whereas those without the lever generally become extremely despairing, exhibiting symptoms which are rather like human clinical depression, becoming withdrawn, anxious and fearful, and not able to recover very well afterwards.

In an experiment over 30 years ago babies were placed under a mobile and some were given a kind of pillow which made the mobile move if their head went into a certain position. Others did not have this pillow. The ones with the special pillow delighted in making the mobile move, but later when all the babies were given that same pillow, only the ones who had already learnt that they could move the mobile by moving their heads on the pillow did so, while the others just did not try (Finkelstein \& Ramey 1977). We see an exaggerated and much more deeply ingrained version of learned helplessness in children who are brought up in deprived situations, such as some forms of institutional care. Once an animal or human child has learnt that they have no power and there is nothing they can do to change their situation, then they do not look for or see opportunities that are actually there. It might sound behavioural but learning is built on prior learning, and therapy can be part of such learning processes. Most research on resilience suggests better outcomes when children and adults feel more positive, feel they can take an active stance and feel confident that the world is predictable and makes sense. A question to ask is how much psychotherapy has a role in facilitating such developments.

\section{Michael}

An adult patient, Michael, who I saw weekly, is typical. He was 34 years old, had barely ever sustained a relationship, and was very unconfident. He had been bullied in school, often felt people were thinking derogatory things about him, and he was all too aware of how needy he was. Women seemed to be put off by his neediness and desperation. He was insightful and very aware of his feelings but seemed to be unable to harness this to break the patterns that continued to make him miserable. His father had been cruel and teasing of him and then had suddenly died when he was 7. He was the youngest sibling and became very close to his mother who also alternated between being extremely kindly and then withdrawing from him.

For the first year or so most of the work was about managing pain and despair. He came in such a state that just containing him and helping him to calm down was all that could be done. In this period he had failed to 
gain various promotions at work, and had fleeting sexual contacts which never lasted more than 48 hours. Each time a potentially interested woman seemed to be quickly put off. Such events triggered the kind of self-hating depressive thinking that crushed him further. The empathy, sympathy and support I had offered at first seemed like a huge relief, but eventually began to feel unhelpful and I worried that things might never change. I found myself wanting to give him a bit of a push, but feared that I was simply re-enacting the way he and others despised his weakness and his despairing 'little boy' ways. In one session he came in after yet another rebuff from a woman he liked, this time one about whom I had thought his hopefulness seemed justified. He described what seemed to me a particularly lame excuse she had given for stopping seeing him, and he went on to tell me how upset he was. He rather plaintively described his fear that he would never have a relationship. He then got a bit angry, complaining that women were liars, they did not really want nice guys, the 'bastards' always did best. This anger seemed significant and gave me some heart, and when he looked at me forlornly I surprised myself by saying 'aren't you going to fight for her?' Equally surprisingly he did, and with some success. He slowly, with the support of therapy, and a new male friend, began to take more risks and be more assertive. I definitely became more actively encouraging of this burgeoning part of his personality, such as when he interviewed for a job successfully or stood up for himself in the office. Yet I still at times felt secretly guilty about this, not on his account, but on account of a psychoanalytic superego whom I heard saying I was being un-psychoanalytic.

Michael still found life tough and at times excruciating, and he needed help with this, but new elements of his personality were growing that allowed him to believe that he could be stronger, and that one setback was not the end of the world. Even when his girlfriend eventually ended the relationship his despair was of a different order. He was angry and upset, yet he was less self-hating. He really felt that something good might come along in time, and he was also able to take some positives from the situation, about what he had gained and learned. Like Carol, he did not just sink into a default pit of despair. I could sympathise with his despair but there were times when I could also teasingly say 'oh dear, then it will be all doom and gloom forever', and he would smile, and rediscover some optimism. He was becoming an active player and not a passive victim. A growing part of him was now on the side of life, possibly of Symington's (Symington 1993) 'life-giver', which seems to be something between a mental state and an internal object. Symington is one psychoanalyst who does not shrink from difficulty but has also maintained a central place for such ideas and writes that 'turning away from the life-giver is a turning against the self. Life is potential for growth.' (p41.)

\section{Some stress is better than no stress but worse than lots of stress}

Whether we bounce back or go under after a trauma is 'overdetermined', and depends on factors such as genetic makeup, early history, social support networks and much more. Some factors turn up time and again as central in the research. Children who experience extremes of stress in early childhood, such as abuse or very early separation, are likely to be more vulnerable to later stressors (Haglund et al. 2007), and to have abnormally high physiological signs of stress as adults. We now know how early stress impacts on primate neurobiology, leading to more anxiety, higher base-line cortisol levels and even lower hippocampal volume, all often seen in survivors of trauma and abuse (Perry et al. 1995). However what is equally important is that a stress-free life is not what is needed. Children who have experienced and come through mild stressors, such as moving home or of a parent becoming ill, in fact seem better equipped to deal with stressors later on in life (Maddi 2005) than those who had a more stress-free early childhood. Such children learn to regulate their own stress response systems. A typical example is that adolescent boys who had survived early difficulties such as ill or divorcing parents, had less reactive heart rates and blood pressure when performing challenging tasks than boys who had had a relatively easier early life (Boyce \& Chesterman 1990)). Too much and/or too overwhelming early stress does not help later on, but interestingly nor does too little, and some exposure to manageable early difficulties seems to be inoculatory. This same stress inoculation model can be seen in most primates. Monkeys separated from their mothers for a manageable period, in this case one hour every 
week, exhibited acute distress, as seen in desperate calling out and higher cortisol levels, but these monkeys in fact coped better later in life with novel situations than those who had not ever been separated, showing less anxiety on all measurements (Parker et al. 2007).

To deal successfully with stress or trauma we need a well functioning reward system in which we look forward to good things and maintain an appetite for life. Resilient individuals tend to have this, and are able to respond appropriately to positive and hopeful experiences, and the system involved with producing dopamine is centrally implicated in this. Trauma and stress have been shown to affect the functioning of our reward and pleasure systems (Bogdan \& Pizzagalli 2006), and research with animals, and clinical accounts with humans have shown how highly stressful experiences can diminish enjoyment and make people averse to social contact. An active coping style is a trait which links with the positive advantages of being more extroverted and was hopefully one that both Carol and Michael were developing. Linked with this, not being an 'ostrich' but rather being able to face one's fears fosters resilience. Facing one's fears and an active coping style are both marked by an ability to 'move towards' experiences, to meet the world 'head-on' rather than shrink from it. This is something we see in happier individuals who have more left hemisphere dominance and are outgoing, reaching out to new experiences, whereas more depressed individuals who show more right brain activity and are more introverted also show more neuroticism, less resilience under stress, and shrink from life more. Interestingly people who are securely attached seem to show more extrovert characteristics (Carver 1997), and whilst the categories are by no means coterminous, there are strong links between insecure attachment and neuroticism, and, as one might expect, a more secure child is likely to be happier, more at ease and confident, and more outgoing. On examining the brain activity of extroverts and introverts having shown all of them both positive images, such as happy couples, sunsets, icecream as well as some negative sadder or potentially more worrying images, the fascinating result emerges that subjects high in neuroticism barely respond to the positive images. Their brain activity was more or less the same while looking at them, but their brains were very active in response to the negative images. The converse was true for extroverts, and there was little brain activity when they were shown more negative images but lots when they were shown the more positive images (Canli et al. 2002). This seems to illustrate graphically how we perceive and react to a version of the world that we expect and understand all too well.

There are inevitably nature/nurture and chicken and egg questions here about what causes what and whether temperament, whether one is like Eeyore or Tigger, is simply a question of genetic inheritance. In fact it seems genetic inheritance has a place but it is experience that turns on and off such potentials. For example serotonin is known to be linked to mood, and well known anti-depressants such as Prozac are targeting the system involved. It seems likely that early anxiety and stress might well down-regulate the receptors in the brain for serotonin, basically stopping people experiencing happiness and also reducing resilience. Depressed patients have less dense serotonin receptors, as do those with panic disorders. However one can also have a genetic predisposition to be more or less receptive to serotonin. A large study in New Zealand (Caspi et al. 2003) divided subjects according to which version they had of a serotonin transporter gene. If they had a 'short' version of the gene they were more likely to be depressed, stressed or anxious. However, whether or not they actually became depressed depended on their experiences. Forty three percent of the people who had this short gene and had at least three tumultuous or adverse experiences became depressed. People with the long version of the gene and similar adverse experiences did not get depressed, nor did those with the disadvantageous short gene who did not have stressful experiences. This is only one example of exciting new research which suggest that temperament is a result of a combination of inherited predispositions and the kinds of experiences one has (Reiss \& Leve 2007).

\section{Conclusions. Resilience, processing emotions, positive feelings, and emotional complexity}

This paper has focussed on the importance of positive experiences and the development of resilience and questioned whether there has been sufficient space for these in psychoanalytic psychotherapy. The argument is not that only good experiences are good for us; in fact some stress is helpful, especially in learning to 
manage later stress, whereas an overload of stress is extremely detrimental. If one thinks of mother-infant interactions, these are rarely smooth, with Tronick (Tronick 2007) and his colleagues suggesting that good mutual attunement occurs only about $30 \%$ of the time. Children are learning to manage 'ruptures and repair' constantly, and this gives rise to resilience, as long as the ruptures are not too catastrophic and the repairs are good enough and quick enough. Resilience does not come from having an easy life with no challenges. Secure children recover better than insecure ones from stressors, it seems because they have an overriding sense already that things will work out for them, that the world is 'good and safe'. Although positive and negative emotions are processed differently, it seems that it is the ability to process both negative and positive affect that is so central, which in effect means having two sets of skills. In one interesting experiment, bereaved men and women had to tell stories about their relationships with their spouses (Bauer $\&$ Bonanno 2001). Those who recovered best were able to tell stories containing both negative and positive emotions. Although I have stressed the role of positive experience, this is not enough on its own, and equally important is the capacity to face and manage negative ones and not be overwhelmed by them. One might say to be positive about, and not shirk from, negative emotions. Those bereaved people with just positive stories recovered less well than those with at least one negative self-statement. This capacity to see two sides of the coin and manage some ambivalent feelings is at the heart of much psychotherapeutic and psychoanalytic theory.

What we see in those able to face adverse experiences is that they do not deny them, or retreat from them, but are able to process and make sense of them. This is echoed in neuroscience thinking. Siegel (Siegel 2007) argued that left brain activation is not just about happy as opposed to unhappy feelings, but also about the ability to 'move towards' experience, an ability seen more in confident and extrovert personalities and less in fearful and neurotic ones with higher right brain activity. The links between left and right brain are also crucial as, Siegel argues, emotional health is strongly related to complexity of neuronal pathways and linkages between different parts of the brain. In experiments people who described themselves in more mixed ways, in terms of positive and negative attributes, were more resilient (Niedenthal \& Showers 1991). It seems that Pangloss' optimism is by no means enough. Those who paint a too-nice vision, with less complexity, in fact turn out to be less resilient to stress. People whose affect dimensions are highly differentiated, who in other words refuse to let any good feelings in with the bad ones or vice versa, tend to do less well. An example of this might be those parents who score 'withdrawn' on the adult attachment interview. They tend to describe their own childhood experiences positively irrespective of the reality, and tend to dismiss and have no room in their mind for the negative; they distance themselves from their children's difficult emotional experiences, and these children are likely to become avoidantly attached.

Whilst psychoanalysis needs to hold onto its focus on difficulty and the negative, it might also need to be better able to conceptualise therapeutic work with the more ' $u p$ ', positive and resilience-building parts of the personality. Kissen (Kissen 1995) for example, has argued, that psychoanalysis needs 'an expansion from conceptions based solely on negative affects ...to a (study of) a broad array of positive affects'. One kind of feeling, whether positive or negative, does not simply 'trump' or override another. Just managing either positive or negative feelings alone is not enough, and children and adults are advantaged if they can manage both sets of feelings. To return to where this paper started, feeling good is not the same as not feeling bad, people need help to manage bad experiences and to be able to have good experiences, especially as good experiences are good for us, and having had them can protect us when bad ones come along.

Graham Music

Tavistock Centre

120 Belsize lane 
London

NW3 5BA

gmusic@tavi-port.nhs.uk

Alvarez, A. (1992) Live company. Tavistock/Routledge London.

Arkin, R., Cooper, H. \& Kolditz, T. (1980) A statistical review of the literature concerning the self-serving attribution bias in interpersonal influence situations 1. Journal of personality 48(4): 435-448.

Balint, M. (1968) The basic fault: Therapeutic aspects of regression. London: Tavistock.

Bauer, J.J. \& Bonanno, G.A. (2001) I can, I do, I am: The narrative differentiation of self-efficacy and other self-evaluations while adapting to bereavement. Journal of Research in Personality 35(4): 424-448.

Bjorklund, D.F. (2007) Why youth is not wasted on the young: immaturity in human development. Oxford: Blackwell.

Bogdan, R. \& Pizzagalli, D.A. (2006) Acute stress reduces reward responsiveness: implications for depression. Biological psychiatry 60(10): 1147-1154.

Bollas, C. (1989) Forces of destiny: Psychoanalysis and human idiom. London: Free Association Books.

Boyce, W.T. \& Chesterman, E. (1990) Life events, social support, and cardiovascular reactivity in adolescence. Journal of Developmental and Behavioral Pediatrics 11(3):105.

Bradburn, N.M. \& Noll, C.E. (1969) The structure of psychological well-being. Chicago: Aldine.

Canli, T. et al. (2002) Amygdala response to happy faces as a function of extraversion. Science 296(5576): 2191. 
Carver, C.S. (1997) Adult attachment and personality: Converging evidence and a new measure. Personality and Social Psychology Bulletin 23(8): 865-883.

Caspi, A. et al. (2003) Influence of life stress on depression: moderation by a polymorphism in the 5-HTT gene. Science 301: 386-9.

Cohen, S. et al. (2006) Positive emotional style predicts resistance to illness after experimental exposure to rhinovirus or influenza A virus. Psychosomatic medicine 68(6): 809-815.

Danner, D.D., Snowdon, D.A. \& Friesen, W.V. (2001) Positive emotions in early life and longevity: Findings from the nun study. Journal of Personality and Social Psychology 80(5): 804-813.

Davidson, R.J. et al. (2003) Alterations in brain and immune function produced by mindfulness meditation. Psychosomatic Medicine 65: 564-570.

Demaree, H.A. et al. (2005) Brain Lateralization of Emotional Processing: Historical Roots and a Future Incorporating" Dominance". Behavioral and Cognitive Neuroscience Reviews 4(1): 3-20.

Dunning, D., Heath, C. \& Jerry, M. (2004) Flawed Self-Assessment: Implications for Health, Education, and the Workplace. Psychological Science in the Public Interest 5(3): 69-106.

Field, T., Diego, M. \& Hernandez-Reif, M. (2006) Prenatal depression effects on the fetus and newborn: a review. Infant Behavior and Development 29(3): 445-455.

Finkelstein, N.W. \& Ramey, C.T. (1977) Learning to control the environment in infancy. Child development 48(3): 806-819.

Francis, D. et al. (1999) Nongenomic transmission across generations of maternal behavior and stress responses in the rat. Science 286(5442): 1155-58. 
Fries, A.B.W. et al. (2005) Early experience in humans is associated with changes in neuropeptides critical for regulating social behavior. Proceedings of the National Academy of Sciences 102(47): 1723717240 .

Glaser, R. et al. (1999) Stress-related changes in proinflammatory cytokine production in wounds. Archives of General Psychiatry 56(5): 450-456.

Gottman, J.M. (1994) What predicts divorce?: The relationship between marital processes and marital outcomes. New Jersey: Lawrence Erlbaum.

Graham, Y.P. et al. (1999) The effects of neonatal stress on brain development: implications for psychopathology. Development and Psychopathology 11(3): 545-565.

Haglund, M.E.M. et al. (2007) Psychobiological mechanisms of resilience: Relevance to prevention and treatment of stress-related psychopathology. Development and Psychopathology 19(3): 889-920.

Helgeson, V.S. \& Fritz, H.L. (1999) Unmitigated agency and unmitigated communion: Distinctions from agency and communion. Journal of Research in Personality 33(2) :131-158.

Horswill, M.S., Waylen, A.E. \& Tofield, M.I. (2004) Drivers Ratings of Different Components of Their Own Driving Skill: A Greater Illusion of Superiority for Skills That Relate to Accident Involvement. Journal of Applied Social Psychology 34(1): 177-195.

Ito, T.A. et al. (1998) Negative information weighs more heavily on the brain: The negativity bias in evaluative categorizations. Journal of Personality and Social Psychology 75(4): 887-900.

Jung, C.G. (1921) Psychological types, Princeton: Princeton University press.

Kiecolt-Glaser, J.K. et al. (2005) Hostile marital interactions, proinflammatory cytokine production, and wound healing. Archives of General Psychiatry 62(12): 1377-1384. 
Kissen, M. (1995) Affect, object, and character structure. Madison, Conn: International Universities Press.

Kohut, H. (1977) The restoration of the self. New York: International Universities Press.

Layard, R. (2005) Happiness: Lessons from a new science, London: Penguin.

Maddi, S.R. (2005) On hardiness and other pathways to resilience. American Psychologist 60(3): 261-2.

Mills, C.M. \& Keil, F.C. (2005) The development of cynicism. Psychological Science 16(5): 385-390.

Milne, A.A. \& Shepard, E.H. (1958) The world of Pooh: containing Winnie-the-Pooh and The house at Pooh Corner. London: Methuen.

Murray, L. (1992) The impact of postnatal depression on infant development. Journal of Child Psychology and Psychiatry 33(3): 543-561.

Niedenthal, P.M. \& Showers, C. (1991) The perception and processing of affective information and its influences on social judgment. In J. Forgas, ed. Affect and social judgment. Oxford: Pergamon, pp. $125-143$.

O'Connor, T.G., Bredenkamp, D. \& Rutter, M. (1999) Attachment disturbances and disorders in children exposed to early severe deprivation. Infant Mental Health Journal 20(1): 10-29.

Parker, K.J. et al. (2007) Early life stress and novelty seeking behavior in adolescent monkeys. Psychoneuroendocrinology 32(7): 785-792.

Perry, B.D. et al. (1995) Childhood trauma, the neurobiology of adaptation, and Huse-dependent" development of the brain: How states" become traits". Infant Mental Health Journal 16(4): 271-291. 
Peterson, C., Maier, S.F. \& Seligman, M.E.P. (1993) Learned helplessness: A theory for the age of personal control. New York: Oxford University Press.

Porter, E.H. (1913) Pollyanna. LC Page.

Reiss, D. \& Leve, L.D. (2007) Genetic expression outside the skin: Clues to mechanisms of Genotypex Environment interaction. Development and psychopathology 19(4): 1005-1027.

Russek, L.G. \& Schwartz, G.E. (1997) Feelings of Parental Caring Predict Health Status in Midlife: A 35Year Follow-up of the Harvard Mastery of Stress Study Journal of Behavioral Medicine 20(1): 1-13.

Seligman, M.E.P. (2002) Authentic happiness: Using the new positive psychology to realize your potential for lasting fulfillment. Free Press.

Siegel, D.J. (2007) The mindful brain: Reflection and attunement in the cultivation of well-being. New York: Norton.

Spitz, R.A. (1945) Hospitalism - An inquiry into the genesis of psychiatric conditions in early childhood. Psychoanalytic study of the child 1: 53-74.

Stipek, D. \& Gralinski, J.H. (1996) Children's beliefs about intelligence and school performance. Journal of Educational Psychology 88(3): 397-407.

Symington, N. (1993) Narcissism: A new theory. London: Karnac.

Tronick, E. (2007) The neurobehavioral and social emotional development of infants and children. New York: Norton.

Tustin, F. (1992) Autistic states in children. London: Tavistock.

Valdimarsdottir, H.B. \& Bovbjerg, D.H. (1997) Positive and negative mood: Association with natural killer 
cell activity. Psychology \& Health 12(3): 319-327.

Voltaire, F.M.A. (1947) Candide, or, Optimism. London: Penguin.

Zautra, A., 2003. Emotions, stress, and health, New York: Oxford University Press. 